
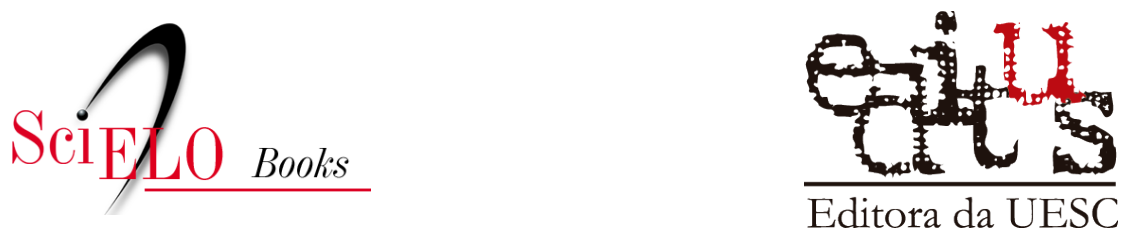

\title{
6 Da voz à letra: oralidade, ancestralidade e resistência
}

\author{
Raíssa Félix
}

\section{SciELO Books / SciELO Livros / SciELO Libros}

FÉLIX, R. Da voz à letra: oralidade, ancestralidade e resistência.

In: Volta miúda: quilombo, memória e emancipação [online]. Ilhéus, BA: Editus, 2020, pp. 147-162. Transfluência series. ISBN: 978-65-86213-14-0. https://doi.org/10.7476/9786586213317.0007.

\section{(c) $\underset{\mathrm{EY}}{ }$}

All the contents of this work, except where otherwise noted, is licensed under a Creative Commons Attribution 4.0 International license.

Todo o conteúdo deste trabalho, exceto quando houver ressalva, é publicado sob a licença Creative Commons Atribição 4.0.

Todo el contenido de esta obra, excepto donde se indique lo contrario, está bajo licencia de la licencia Creative Commons Reconocimento 4.0. 


\section{Da voz à letra: oralida- de, ancestralidade e resistência}

O dom da palavra - que é vida - permeia a existência de Domingos Serafim, com humor peculiar, sentado à sombra de um coqueiro em frente a sua casa, em Volta Miúda, ele rememora o passado e reflete: "quem é que não gosta de uma coisa boa?". E ele continua, "Tenho meu respeito com quarquer um, mas também se a gente não fizer graça morre à toa, viu?" (Domingos Serafim, 9 de junho de 2018), contar histórias, relembrar o vivido, recompor imagens, feições, reações, expressar o risível lhe garantem a vida.

Nascido e criado em Volta Miúda, Domingos Serafim conta que "Quando tomei entendimento de gente, ainda topei o cheiro dos escravo, escravo trabalhava debaixo de taca, dona Raíssa" (9 de junho de 2018). O narrador perdeu a visão por volta do início da década de 1990 e talvez por isso construa a cena da violência implementada contra o seu povo a partir da percepção olfativa figurada. Outra explicação possível à sua menção ao "cheiro" é que advenha da sua experiência e ancestralidade, haja vista que esse sentido 
aparece como um descritor muito comentado no século XIX, embora associado à discriminação e repulsa da participação dos negros nos ambientes sociais. Cláudio de Paula Honorato, em dissertação acerca do "Valongo: o mercado de escravos do Rio de Janeiro, 1758-1831", cita:

Os viajantes que por aqui passaram deixaram registrados diversos comentários sobre a exuberante beleza natural a grande luminosidade de cores e tons, mas reclamavam do excessivo calor, dos cheiros desagradáveis e mostravam-se amedrontados pela enorme quantidade de negros nas ruas. A mesma cidade que atraía, causava medo e insegurança. Pairava sobre essa elite o medo, andavam receosos pelos becos e vielas em geral estreitos e irregulares, sujos, mal cheirosos e sombrios onde se amontoavam um grande número de escravos, mendigos e desocupados, excluídos da sociedade, destituídos de quaisquer direitos, mas sempre prontos a mostrar sua presença e suscitar o imaginário de uma elite que já na época temia a africanização do Brasil. (HONORATO, 2008, p. 45-46, grifos meus).

As falas de Seu Domingos carregam forte ligação com a experiência vivida com os seus ascendentes, as memórias denunciam e/ou expressam o processo de violência a que foram submetidos os ancestrais: "Vó Júlia falava que com o escravo era assim: botava, futucava formiga preta e botava criança lá, pra formiga preta mordê... não podia chorar, é verdade, escravo disse que foi duro, e hoje tem, tem uma catingazinha, um cheirozinho de escravo". As histórias contadas pela avó Júlia são compartilhadas em paralelo à afirmação de que Volta Miúda é uma comunidade feliz, informando o cheiro como reflexo do estado de continuidade em que resiste a negritude quilombola de Volta Miúda. 
Ao se debruçar sobre a figura do narrador - este sujeito que conta, relata, apreende experiências próprias e de outrem e as repassa -, Walter Benjamin (1994, p. 221) chega à conclusão de que "Seu dom é poder contar sua vida; sua dignidade é contá-la inteira”. A inteireza aduzida por Benjamin suscita dúvidas, possibilita a amplitude interpretativa. Para ele, narrar não se trata da concatenação de fatos, mas da exposição de experiências em intercâmbio. Com deferência, o autor afirma que, com capacidade cada vez mais rara, "o narrador figura entre os mestres e os sábios. Ele sabe dar conselhos: não para alguns casos, como o provérbio, mas para muitos casos, como o sábio. Pois pode recorrer ao acervo de toda uma vida" (BENJAMIN, 1994, p. 221). A inteireza referida por Benjamin parece menos relacionada à exigência de muitas experiências do que à relação holisticamente implicada que o narrador estabelece com as vivências em intercâmbio. Assim como aponta Hampâté Bâ (2010, p. 199) sobre os griots genealogistas, que se constituem autoridades por preservar a história e, com ela, a inteireza que conforma o mundo e a alma africana.

Narrar é, pois, uma forma comunicacional descompromissada com o imediatismo, do qual a informação é vassala. Opõe-se, portanto, à volatilidade incutida pelas relações sociais que vão se consolidando com a burguesia e no contexto do regime capitalista. O agora, a urgente entrega para compreensão, ainda que superficial, da informação, é rejeitada pela arte da narrativa, que se vincula ao sentir, à senciência ${ }^{10}$ para admitir que a escuta digna se concebe com a abertura do ouvinte à integração do narrado com a sua própria experiência. Como ensinou o filósofo, "Quanto mais o ouvinte se esquece de si mesmo, mais profundamente se 
grava nele o que é ouvido" (BENJAMIN, 1994, p. 205), trata-se, portanto, de encontro, da refutação da individualidade e competitividade incentivadas pelo sistema-mundo moderno-capitalista.

A oralidade, nas tradições africanas, além de valor moral possui caráter sagrado, é definida por ele como o conhecimento total: "Fundada na iniciação e na experiência, a tradição oral conduz o homem à sua totalidade e, em virtude disso, pode-se dizer que contribui para criar um tipo de homem particular, para esculpir a alma africana" (HAMPÂTÉ BÂ. 2010, p. 170). No mesmo sentido, Zumthor (2010, p. 15), ao referir-se às tradições africanas, atribui capacidade transformadora e curativa à oralidade:

Ora, a voz é querer dizer e vontade de existência, lugar de uma ausência que, nela, se transforma em presença; ela modula os influxos cósmicos que nos atravessam e capta seus sinais: ressonância infinita que faz cantar toda matéria (ZUMTHOR, 2010, p. 9).

Perceber a dominação fundada na hierarquização sociocultural e a repulsa do sistema-mundo colonial capitalista a individualidades que não se adequam ao sentido do lucro e da produtividade é admitir que estejam sujeitas a uma destruição sistemática desde o nascimento (BOSI, 1994, p. 80). A decadência da arte de contar histórias e trocar experiências alija da integração social grupos de tradição oral - tais como povos indígenas, africanos e afrodescendentes - e, em outro paralelo, os anciãos. Para estes, há ruptura da comunicação com o desestímulo ao diálogo que, em via dupla, afeta narrador e ouvinte. Após uma vida de aprendizagens 
e experiências, o sujeito envelhecido, um narrador por excelência ou por força das circunstâncias da senilidade, perde a capacidade e/ou o meio de transmiti-las, o sentimento de continuidade é afetado pela sociedade industrial, que the retira, então, a dignidade.

"Que é, pois, ser velho na sociedade capitalista?", questiona Marilena Chauí, ao prefaciar Ecléa Bosi, referindo-se ao velho urbano, ignorando o recorte racial, "É sobreviver. Sem projeto, impedido de lembrar e de ensinar, sofrendo as adversidades de um corpo que se desagrega à medida que a memória vai-se tornando cada vez mais viva, a velhice, que não existe para si mas somente para o outro [opressor]" (CHAUÍ, 1994, p. 18-19). Falar sobre as/os anciãs/os de Volta Miúda é adentrar ao espectro em que a velhice no contexto capitalista se intersecta com a negritude, gênero e a ruralidade. Compreendendo-se que o desfazimento da identidade favorece o controle, visto que "um homem não sabe o que ele é se não for capaz de sair das determinações atuais", o movimento de retorno à oralidade - "atmosfera sagrada" (BOSI, 1994, p. 91) - é, nesta perspectiva, hábil à devolução da vida. "Para que nenhuma forma de humanidade seja excluída da humanidade é que as minorias têm lutado, que os grupos discriminados têm reagido" (BOSI, 1994, p. 81), e é por meio da interculturalidade ${ }^{11}$ premente na oralidade - esta região fronteiriça que integra narrador e ouvinte -, sob uma perspectiva crítica, que se pode contribuir à deflagração das estruturas que fomentam a excludente estrutura social.

Inobstante as influências do materialismo histórico ${ }^{12}$, o que se quer é refletir quanto ao desestímulo do exercício
11. A interculturalidade, ao contrário do multiculturalismo, pressupõe o "reconhecimento recíproco e disponibilidade para enriquecimento mútuo entre várias culturas que partilham um dado espaço cultural" (SANTOS, 2009, p. 9).

12. Marco teórico que atribui às mudanças tecnológicas e ao modo de produção fatores principais de mudança social, política e jurídica. Conforme Karl Marx (1859, p. 338), “O sistema de produção da vida material condiciona todo o processo da vida social, política e espiritual". 
dialógico, o qual, fomentado pelas mutações comunicacionais com o advento do capitalismo e globalização, também Ihes serve de motor. Há aqui uma retroalimentação sistemática: a tradição oral é olvidada em função de formas comunicacionais modernas, especialmente pela imposição da linguagem escrita, que contribui ao processo de silenciamento e dominação das nações, povos e etnias de tradição oral, que são subalternizados. Contextualizar este processo evoca, conforme Rita Segato (2017, p. 49), a discussão sobre o racismo estrutural, fatores, valores e práticas que contribuem para o estabelecimento de pessoas não brancas em posições de menor prestígio e autoridade. Racismo que torna vítimas "aquellos que conjugan una diferencia racial, un signo fenotípico, con un patrimonio cultural idiosincrático. Se trata, entonces, de un grupo étnico-racial discriminado" (SEGATO, 2017, p. 45), a exemplo das populações quilombolas no Brasil.

É importante elucidar que a utilização de códigos escritos para a comunicação não é uma habilidade exclusiva das nações europeias, visto que sociedades latino-americanas - a exemplo dos incas, maias e astecas - muito antes das invasões colonialistas, eram adeptas da linguagem escrita. O que as diferenciam, entretanto, é a relação travada com e a partir desta, em parte pelo protagonismo atribuído à letra em detrimento da oralidade e o fato das nações europeias imporem a sua experiência comunicacional como paradigma de legitimação de toda organização social e epistêmica. Ao questionar a hierarquia implementada pelos colonizadores, Diana Taylor (2013, p. 136-137) problematiza que "se a memória coletiva se apoia em estruturas sociais para possibilitar a transmissão, as práticas comportamentais que definem 
a etnicidade participam dessa transmissão". Portanto, a negação à estrutura elementar mnemônica dos povos de tradição eminentemente oral culmina no aprisionamento dos próprios corpos.

Com certo grau de ironia, Hampâté Bâ (2010, p. 168) pergunta: "Não faz a oralidade nascer a escrita, tanto no decorrer dos séculos como no próprio indivíduo?", decerto que, se se considerasse legítima a hierarquização sociocultural, há uma inversão inevitável de posições. O xamã Yanomami Davi Kopenawa, em livro com relatos seus reunidos pelo etnólogo Bruce Albert, também rechaça a relação de inferioridade atribuída à oralidade e tece crítica aos "brancos", aduzindo uma limitação não apenas cognitiva como metafísica à cultura moderna/eurocentrada:

Os brancos se dizem inteligentes. Não o somos menos. Nossos pensamentos se expandem em todas as direções e nossas palavras são antigas e muitas. Elas vêm de nossos antepassados. Porém, não precisamos, como os brancos, de peles de imagem para impedi-las de fugir da nossa mente. Não temos de desenhá-las, como eles fazem com as suas. Nem por isso elas irão desaparecer, pois ficam gravadas dentro de nós. Por isso nossa memória é longa e forte. [...]

Omama não nos deu nenhum livro mostrando os desenhos das palavras de Teosi, como os dos brancos. Fixou suas palavras dentro de nós. Mas, para que os brancos as possam escutar, precisam que sejam desenhadas como as suas. Se não for assim, seu pensamento permanece oco. Quando essas antigas palavras apenas saem de nossas bocas, eles não as entendem direito e as esquecem logo. (KOPENAWA; ALBERT, 2015, p. 75-77). 
Para o xamã, contar histórias, um aprendizado ancestral, perfaz um instrumento para elucidação das ambiguidades do presente, é exercício que emana dos próprios deuses, ou melhor, espíritos, que sustentam o céu e que explicaram, desde os antepassados, que o vilipêndio à natureza - se os brancos insistirem em destruí-la - secará a terra, rachará as pedras no calor, murchará as árvores, fará com que os rios desapareçam debaixo da terra e o chão se desfará. Silenciosa e ressecada a terra, os xamãs morrerão e, não mais havendo quem sustente o céu, ele desabará (KOPENAWA; ALBERT, 2015, p. 492-494).

Ritos e fé, comportamento e organização coletiva, estão interligados. Kopenawa, ao falar sobre o seu povo, conta sobre uma vivência implicada à sustentação do próprio mundo, relação de causalidade que se distancia da cultura de satisfação individualista presente na modernidade e que, por muito tempo, propagou negros e índios como povos aculturados, destituídos de civilidade e humanidade. Diana Taylor (2013, p. 134) enfatiza: "As estruturas mentais - que incluem imagens, histórias e comportamentos - constituem um arquivo e um repertório específicos. A raça é construída socialmente", a desconstrução do lugar cênico subalterno atribuído aos povos colonizados e escravizados, negros e indígenas perpassam, então, pela refutação da linguagem escrita como paradigma de validação da experiência, da ciência e da fé.

A discussão acerca da narrativa, da linguagem enquanto performance que reflete e é a própria identidade, composta por um conjunto mnemônico singular, conduz à memória (e a história) enquanto direito elementar à 
consecução da dignidade humana (BRASIL, 1988, art. 5 , $\$ 2^{\circ}$, p. 215-216), pois, manipulando-se a linguagem, perde o indivíduo o vínculo contínuo a partir do qual transcende a sua cultura e origem. Sem a efetivação deste direito à memória, condena-se os descendentes diretos e indiretos dos povos que não compartilham do corpus cultural eurocentrado ao limbo identitário.

A memória é um objeto inacabado, socialmente construído - como também o é a raça -, elemento constitutivo da identidade. Portanto, o controle da linguagem relaciona-se à memória, pois as narrativas olvidadas afetam sujeitos em sua dimensão individual e, em escala mais ampla, afetam a memória coletiva (POLLACK, 1992) e, enquanto objeto de disputa política, a memória manipulada à esteira da história oficial celebrativa, aliena o sujeito. Do ponto de vista jurídi$c o$, toda política de discriminação que restringe, em função da origem étnica, o "reconhecimento, o gozo ou o exercício, em igualdade de condições, dos direitos humanos e das liberdades fundamentais nos domínios político, econômico, social, cultural" (BRASIL, Art. $1^{\circ}$, s1, 1969), é considerada racismo, o alijamento do direito à memória é uma forma de racismo estrutural e estruturante da sociedade. A refutação da arte narrativa enquanto estratégia política (de dominação) é também racismo, pois, na medida em que a linguagem escrita é imposta, não se trata mais de escolha, mas de intencionalidade deletéria a uma concepção plural e democrática de sociedade.

Esta discussão remonta à colonização dos territórios latino-americanos, como no caso do Brasil invadido pelos portugueses em 1500 d. C. - embora a história oficial por 
13. "Colonialidade do poder é um conceito que dá conta de um dos elementos fundantes do atual padrão de poder, a classificação social básica e universal da população do planeta em torno da ideia de 'raça'", (QUIJANO, 2002, p. 4). muito tempo tenha obrigado à versão da "descoberta". A normalidade social atual erigiu-se do massacre e exploração da força de trabalho de negros e índios, não cidadãos privados de qualquer sentido de dignidade ou direitos - fala-se aqui do controle não apenas da matriz intangível das suas origens, mas da sangria de corpos que foram desumanizados. Furtar-se de problematizar a interação cultural - tal qual já foi demonstrado, no que tange à relação travada com a oralidade - é fomentar que não mais a colonização, mas a colonialidade ${ }^{13}$ se protraia sobre os corpos e saberes, impedindo a realização de uma independência de fato e não apenas de direito.

A racialização é fator impeditivo da liberdade, constituiu-se numa marcação fenotípica e cultural, demarcatória da linha abissal que generaliza, subalterniza e diferencia as sociedades não brancas dos países que dominam o mundo, conforme a perspectiva destes. Por outro lado, em cada um desses países subalternizados, "a lo largo de su historia, se ha instalado una matriz de construcción de alteridad racialmente marcada al interior, que sirve de base para los mecanismos de exclusión por parte de las élites que controlan el Estado y sus recursos". (SEGATO, 2017, p. 50). Há transmutação terminológica, mas sem que haja perda do sentido elementar da opressão. A colonização perfez-se em colonialidade e o imperialismo dialoga com os mecanismos de dominação real e simbólica que deturpam a representação social e legitimam as relações sociais baseadas nos critérios de classificação e exclusão (QUIJANO, 2009). A subalternização de grupos atende de forma sistemática aos interesses imperialistas e a divisão étnico-racial faz-se instrumento de controle. Enquanto os brancos, outrora colonizadores, 
mantêm a sua autoridade, os colonizados, postos à margem social, histórica, cultural, científica e geográfica, são desenhados com a pele não branca dos escravos e mestiços descendentes errantes que contestam, por uma questão de concepção, o sistema de divisão social étnico-racial.

A negação, repressão ou silenciamento das histórias, memórias e perspectivas de mundo de comunidades como Volta Miúda relacionam-se a circunstâncias históricas e políticas que matam, se não o corpo, a liberdade de discernimento daqueles que descendem desta tradição e são alijados de suas origens. Este contexto de opressão se desenvolve por meio do racismo epistêmico e também em outras dimensões de enfrentamentos, a exemplo do processo de sufocamento que sofre o quilombo de Volta Miúda em função do alastramento da monocultura do eucalipto capitaneado por empresas multinacionais. A ação deletéria das empresas se dá com a invasão das comunidades quilombolas, pulverização de agrotóxicos herbicidas/pesticidas por via aérea, captação ilegal de água e contaminação e seca de córregos e nascentes $^{14}$, e culmina na marginalização da comunidade local e precarização das condições de sobrevivência, conforme relata Brasília Firmina:

O Eucalipto tomô o mundo tudo. Por isso que num, tem nada pra povo comê mais. Porque é só Eucalipto que tem. E puxa muita água também. Aqui tinha uma lagoa, que nois pra ir, pra passar lá pra dentro, nois tinha que rodiar ela assim ó... Aí, assim, nois tava escutando "uuuuuuuuuh", a água saindo da lagoa, tem um bocotó fundo aí ó, aqui assim ó. A água descia lááá embaixo. Hoje a lagoa é pura lenha, madeira, não é. Não é varinha não, é madeira grossa que tem dentro da lagoa. (Brasília Firmina, 3 de março de 2019).
14. Denúncias obtidas no Vídeo-documentário "Cartografando Conflitos" (CORNAVACA et al, 2018). 
As palavras de Brasília Firmina manifestam, ainda, o racismo ambiental, além de epistêmico, a que a comunidade tem sido submetida, isso conforme a definição de Tânia Pacheco:

Chamamos de Racismo Ambiental às injustiças sociais e ambientais que recaem de forma implacável sobre grupos étnicos vulnerabilizados e sobre outras comunidades, discriminadas por sua 'raça', origem ou cor [...] O Racismo Ambiental não se configura apenas através de ações que tenham uma intenção racista, mas igualmente através de ações que tenham impacto racial, não obstante a intenção que lhes tenha dado origem. (PACHECO, 2008, p. 9).

É possível identificar pelo menos três aspectos que denotam o racismo ambiental: a desterritorialização da comunidade quilombola pela marginalização da população a direitos sociais, descaracterização da cultura e modo de vida, expropriação da terra por via direta e indireta. Pensar a manutenção da comunidade não se trata de discutir o seu isolamento, mas em refletir que o contato não se dê de forma hierarquizada e deletéria aos seus interesses e modos de existência particulares.

Decerto que as diferenças socioculturais, religiosas, econômicas intersectam-se e se influenciam mutuamente nos territórios colonizados, a dimensão relacional da interculturalidade fala sobre este intercâmbio, contudo, a sua leitura exige uma percepção crítica apta a perceber os conflitos que lhes são inerentes. A interpretação crítica intercultural trata-se de um processo dialógico e não acabado, definido por Catherine Walsh ([entre 2009 e 2019], p. 3) como "uma estratégia, ação e processo permanentes de 
relação e negociação entre, em condições de respeito, legitimidade, simetria, equidade e igualdade" que pugna pela desnaturalização dos lugares sociais que definem, a partir de características sociais e históricas, sujeitos como centrais e subalternizados e condicionam a experiência destes à marginalidade.

Compreender as possibilidades interpretativas a partir da interculturalidade crítica permite rechaçar estratégias de silenciamento ocultadas por uma interação acrítica, estratégias estas que muito longe de derivarem de uma decisão estética são pontos de ruptura que desfavorecem uma visão de mundo comunitária, dialógica e participativa. Dona Zelita (Joselita Aleixo Serafim, 24 de junho de 2018) dimensiona o impacto do silenciamento destas formas de ser e viver: "Ah, de vez im quando a saudade é tão grande, tão grande, que dá vontade de juntá meus pano e ir embora" mas o "embora" não é, necessariamente, lugar (geográfico). Ao expressar o sentimento de pesar, Dona Zelita fala sobre referências de vida que já não encontra mais na comunidade, a maneira cooperativa com que as relações se estabeleciam, "é uma saudade tão grande que dói tudo por dentro". Sua visão de mundo se contrapõe ao "pensamento dos brancos", de uma matriz colonial-capitalista, que segue os caminhos da mercadoria (KOPENAWA; ALBERT, 2015, p. 65).

A memória segue o fluxo de refutação de verdades e certezas e do alargamento de possibilidades de horizontes, a fala é força, porque gera movimento e ritmo e vida e ação (HAMPÂTÉ BÂ, 2010, p. 173), a palavra humaniza e, ao reconhecer que o seu silenciamento é vetor de uma política de apaziguamento/desumanização, trilhar o caminho que 
rememora os sons ocultos pelo silêncio é ratificar a pujança para liberdade que toca a palavra memorada.

Justiça social e justiça cognitiva são temas indissociáveis, sustenta Maria Paula Meneses (2016), e conjuntamente demandam a releitura da História e a ampliação de fontes e métodos desde o Sul - conceito associado às "epistemologias do Sul" (SANTOS, 2009, p. 7-18), que aduzem acerca da produção de conhecimento a partir da experiência e saberes de povos e individualidades subalternizadas, sob a perspectiva de que "todos os conhecimentos sustentam práticas e constituem sujeitos" (SANTOS, 2009, p. 49). Valendo-se da interculturalidade crítica, a hibridização entre forma e conteúdo comunicacional é apresentada como estratégia decoIonial. Isto significa admitir a oralidade na produção científica e pô-la, assim como os saberes que dela advêm, em meio hábil à sua disseminação, o que reforça a perspectiva e importância da rememoração como estratégia de dignificação e humanização das comunidades, haja vista que

restituir a humanidade ao 'homem negro', ultrapassar a exclusão epistémica e a negação ontológica a que tem estado sujeito, é uma das dimensões fundamentais de qualquer projeto de justiça. Enquanto desafio ético, a justiça cognitiva é uma condição para a mudança radical da injustiça trazida pelo projeto colonial-capitalista, onde a epistemologia, em lugar de ser singular, é vista como processo de negociação e diálogo entre saberes. (MENESES, 2016, p. 176).

Retomando a oralidade e o seu poder de criação, Hampâté Bâ (2010, p. 172) explica que "sendo a fala a exteriorização das forças, toda manifestação de uma só força, seja 
qual for a forma que assuma, deve ser considerada como sua fala. É por isso que no universo tudo fala: tudo é fala que ganhou corpo e forma". A tangência da palavra passa, também, pela escrita que, numa perspectiva libertária, não Ihe seja mecanismo de legitimação, mas instrumento performático de transmissão e difusão àqueles que, ainda que não partilhem do contexto local da narrativa, possam dela beber e (res)significar a própria existência. O sujeito moderno é, inevitavelmente, um indivíduo de fronteiras - aprender sobre uma possibilidade decolonial de existência é ampliar seu próprio horizonte de buscas, para além da homogeneização e liquidez incutidas pela modernidade hegemonizada.

De certa forma, abrir espaço à fala é prover novas possibilidades de sentir. A escarificação promovida pela sociedade industrial é anestésica ou, no mínimo, desencorajadora da vida. "O homem moderno, imerso na multiplicidade de ruídos e informações, vê suas faculdades se atrofiarem progressivamente" (HAMPÂTÉ BÂ, 2010, p. 208) - e, por isso, tornam-se cada vez mais raros os narradores. A condição para (re)descobrir um (novo) mundo é exatamente esta: "saber esquecer seu próprio mundo" e "saber renunciar ao hábito de julgar tudo segundo critérios pessoais" (HAMPÂTÉ BÂ, 2010, p. 212). Trata-se de reaprender a sentir e a perceber o outro - não mais como o opressor. Aimé Cesáire (1978, p. 23-24), ao tecer crítica ao colonialismo, escreve, no contexto após a II Guerra Mundial, acerca do racismo e compara-o ao nazismo, alertando: o "colonizador, para se dar boa consciência, se habitua a ver no outro o animal, se exercita a tratá-lo como animal, tende objetivamente a transformar-se, ele próprio, em animal", em razão do que se defende que o principal exercício decolonial é ver ao próximo como ser humano para, quem sabe assim, humanizar-se. 
Narrar, memorar, é traduzir-se, continuar-se a partir da exteriorização de uma perspectiva de vida particular e única. Ao passo em que ouvir, capacidade muito antes olvidada do que a extinção de narradores (BENJAMIN, 1994, p. 205), é componente elementar do encontro de que necessita o diálogo. E é a problematização crítica do ambiente limítrofe que evoca a discussão sociopolítica e exige o desempenho de estratégias para a materialização de uma alternativa de vida e conhecimento aos sujeitos modernos e que são, intrinsecamente, decoloniais e discordantes das estratégias de dominação pela abstração da humanidade. Nesse ensejo, compreendendo-se que a ciência é uma das linhas demarcatórias das disparidades é que se insere a proposição de diálogos a acessar estas vivências olvidadas pela modernidade eurocentrada e em formato eficiente à sua difusão, em especial, em ambientes formais de ensino, concebendo-se, então, a ideia da criação de um livro composto por perfis biográficos de anciãs e anciãos de uma comunidade quilombola, Volta Miúda, pertencente ao município de Caravelas, no Extremo Sul da Bahia, a partir da oralidade. Compreende-se, portanto, que as lembranças da escravidão advêm da continuidade possibilitada pelo diálogo com ascendentes e a fronteira em que se insere, do pós-abolição, o faz ponte que transcende as experiências para o presente. São memórias coletivas que, conforme Maurice Halbwachs (2006, p. 30), permanecem “porque jamais estamos sós. Não é preciso que outros estejam presentes, materialmente distintos de nós, porque sempre levamos conosco certa quantidade de pessoas que não se confundem". 